University of Rhode Island

DigitalCommons@URI

Civil \& Environmental Engineering Faculty

Publications

Civil \& Environmental Engineering

8-23-2019

\title{
Dynamic compressive behavior of metallic particulate-reinforced cementitious composites: SHPB experiments and numerical simulations
}

\author{
Sami Doner \\ Sumeru Nayak \\ Koray Senol \\ Aun Shukla \\ University of Rhode Island, shuklaa@uri.edu \\ N.M. Anoop Krishnan \\ Follow this and additional works at: https://digitalcommons.uri.edu/cve_facpubs
}

The University of Rhode Island Faculty have made this article openly available.

Please let us know how Open Access to this research benefits you.

This is a pre-publication author manuscript of the final, published article.

Terms of Use

This article is made available under the terms and conditions applicable towards Open Access

Policy Articles, as set forth in our Terms of Use.

\section{Citation/Publisher Attribution}

Doner S., Nayak S., Senol K., Shukla A., Krishnan N.M.A, Yilmazcoban KI, Das S., (2019) “ Dynamic Compressive Behavior of Metallic Particulate-reinforced Cementitious Composites: SHPB Experiments and Numerical Simulations", Construction and Building Materials, 227, 116668. https://doi.org/10.1016/ j.conbuildmat.2019.08.049

This Article is brought to you for free and open access by the Civil \& Environmental Engineering at DigitalCommons@URI. It has been accepted for inclusion in Civil \& Environmental Engineering Faculty Publications by an authorized administrator of DigitalCommons@URI. For more information, please contact digitalcommonsgroup@uri.edu. 


\section{Authors}

Sami Doner, Sumeru Nayak, Koray Senol, Aun Shukla, N.M. Anoop Krishnan, Ibrahim Kutay Yilmazcoban, and Sumanta Das

This article is available at DigitalCommons@URI: https://digitalcommons.uri.edu/cve_facpubs/44 


\title{
Dynamic Compressive Behavior of Metallic Particulate-reinforced Cementitious Composites: SHPB Experiments and Numerical Simulations
}

\author{
Sami Doner ${ }^{1}$, Sumeru Nayak ${ }^{1}$, Koray Senol ${ }^{2}$, Arun Shukla ${ }^{3}$, N. M. Anoop Krishnan ${ }^{4}$, Ibrahim \\ Kutay Yilmazcoban ${ }^{5}$, Sumanta Das ${ }^{6 *}$ \\ ${ }^{1}$ Graduate Student, Civil and Environmental Engineering, University of Rhode Island, Kingston, RI, USA \\ ${ }^{2}$ Graduate Student, Department of Mechanical, Industrial and Systems Engineering, University of Rhode \\ Island, Kingston, RI, USA \\ ${ }^{3}$ Simon Ostrach Professor, Department of Mechanical, Industrial and Systems Engineering, University of \\ Rhode Island, Kingston, RI, USA \\ ${ }^{4}$ Assistant Professor, Department of Civil Engineering, Indian Institute of Technology Delhi, Hauz Khas, \\ New Delhi, India \\ ${ }^{5}$ Assistant Professor, Department of Mechanical Engineering, Sakarya University, Sakarya, \\ Turkey \\ ${ }^{6 *}$ Assistant Professor, Civil and Environmental Engineering, University of Rhode Island, Kingston, RI \\ 02881, USA, \\ *corresponding author; Email: sumanta das@uri.edu
}

Doner S., Nayak S., Senol K., Shukla A., Krishnan N.M.A, Yilmazcoban KI, Das S., (2019) "Dynamic Compressive Behavior of Metallic Particulate-reinforced Cementitious Composites: SHPB Experiments and Numerical Simulations", Construction and Building Materials, 227, 116668.

https://doi.org/10.1016/i.conbuildmat.2019.08.049

\begin{abstract}
An experimental and numerical evaluation on the dynamic compressive response of mortars containing up to $20 \%$ waste iron powder as sand replacement is presented in this paper. The dynamic response is evaluated using split Hopkinson pressure bar (SHPB) apparatus under high strain rates (up to 250/s). The elongated iron particulates present in the iron powder-incorporated mortars warrant significantly improved compressive strength and energy absorption capacity at high strain rates. Multiscale numerical simulations are performed with a view to develop a tool that facilitates microstructure-guided design of these particulate-reinforced mortars for efficient dynamic performance. The dynamic compressive response of particulate-reinforced mortars is simulated adopting a numerical approach that incorporates strain rate-dependent damage in a continuum micromechanics framework. The simulated dynamic compressive strengths and energy absorption capacities for mortars with various iron powder content exhibit good correlation with the experimental observations thereby validating the efficacy of the simulation approach.
\end{abstract}

Keywords: Iron powder; dynamic compressive response; split Hopkinson pressure bar; high strain rate; multiscale numerical simulation 


\section{INTRODUCTION}

Portland cement concrete is the single most extensively used material in the construction sector. However, it belongs to the family of quasi-brittle materials that exhibit poor fracture resistance under static and dynamic loading conditions [1,2]. Concrete structures such as buildings, bridges and dams are often subjected to dynamic loads $[3,4]$. In addition, human-made high strain rate events such as terrorist attacks in recent years pose severe threat to the security of the common life all over the world. The motivation of the current study emanates from addressing the aforementioned concern of poor performance of portland cement concrete under dynamic loading conditions towards utilization of waste materials in concrete to develop a material that provides improved performance under high strain rates.

Previous researches have shown that addition of fibers enhances performance of concrete under impact loads [3,5-7]. Yang et al. [8] evaluated the dynamic compressive behavior of concrete containing recycled tire rubber. The influence of steel fiber on the dynamic response of concrete has been shown to enhance the dynamic compressive behavior of concrete [9-12]. Enhanced dynamic compressive response of polypropylene fiber-reinforced concrete has been also reported [13]. Giner et al. [14] reported the dynamic response of carbon fiber-reinforced concrete. Su et al. [3] evaluated the dynamic behavior of ceramic fiber-reinforced concrete using split Hopkinson pressure bar (SHPB) tests [15-21] and the results suggest significant gain in dynamic strength and elastic modulus of concrete [3]. While the previous articles evaluated the influence of fibers on the dynamic behavior of cementitious materials, this paper reports on the dynamic compressive behavior of mortars containing up to $20 \%$ metallic waste iron powder. This iron powder is generated as waste material in the electric arc furnace (EAF) during manufacturing of steel [22-24]. Several million tons of such waste metallic iron powder is being landfilled globally $[22,24]$ since recycling iron from such waste dust is not viable form the economic standpoint. Thus, incorporation of such waste iron powder in cementitious materials is expected to be a cost-effective approach and it will potentially be beneficial from solid waste minimization point of view. The iron particles in this dust have been shown to significantly increase crack growth resistance in mortars $[24,25]$ as well as alkali-activated slag-based geopolymer binders [26] under quasi-static flexural loading conditions due to elongated shape of iron particulates in the powder [23]. This paper performs SHPB tests to obtain dynamic strain rate-dependent compressive responses of waste iron powder-incorporated mortars to elucidate the influence of iron particulates on the high-strain rate compressive behavior of the mortars. The iron particulates with an elongated configuration in the iron powder are expected to enhance the dynamic compressive strength well as energy absorption capacity of mortars which are 
explored in detail in this paper. In addition to the experimental evaluations, this paper also aims to establish a numerical tool towards multiscale simulation-based design of particulate-reinforced cementitious composites for efficient performance under high strain rates. The numerical approach implements numerical homogenization to obtain effective strain rate-dependent compressive constitutive responses employing a strain rate-dependent damage model $[27,28]$ under continuum micromechanics framework. The model incorporates damage at the inclusion-matrix interfaces at the prepeak regime as well as matrix damage in the post-peak regime to simulate the composite strain ratedependent compressive constitutive response. The simulated dynamic compressive responses for iron particulate-reinforced mortars are compared with the experimental observations from the SHPB test for validation. Overall, the current study intends to perform an experimental and numerical investigation to evaluate the effect of iron powder-incorporation on the dynamic compressive response of mortars under high strain rates.

\section{EXPERIMENTAL PROGRAM}

\subsection{Materials and mixture proportions}

Commercially available Type I/II ordinary portland cement (OPC) is used as the main binder in this study. It conforms to ASTM C150. The chemical composition of OPC are shown in Table 1.

Table 1. Oxide content (\%) of elements in OPC

\begin{tabular}{cccccccccc}
\hline Component & Ca & Fe & Al & Si & Mg & S & K & Na & Rest \\
\hline Oxide content (\%) & 63 & 3.47 & 3.61 & 21 & 3.26 & 3.04 & 0.36 & 0.16 & 2.13 \\
\hline
\end{tabular}

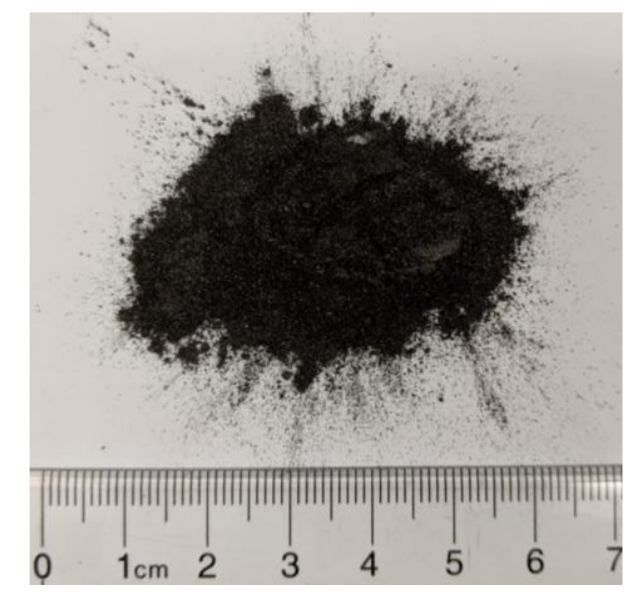

Figure 1: Waste iron powder used as a sand replacement 
Waste iron powder (Figure 1) is used as particulate-reinforcement in this study. The median particle size of iron powder is $19 \mu \mathrm{m}[22,25]$. Silica sand with average particle size of $600 \mu \mathrm{m}$ was used to prepare the mortar mixtures.

In this study, three different mortar mixtures were proportioned with a constant $50 \%$ paste volume and water-to-cement ratio of 0.5 (mass-based). In the three mortar mixtures, sand was replaced with 0,10 and $20 \%$ waste iron powder by volume. The iron powder content beyond $20 \%$ has not been considered here since dosage of iron powder higher than $20 \%$ as sand-replacement does not exhibit satisfactory rheological behavior. The flowability of the mixtures with various dosage of iron powder is evaluated as per ASTM C1810 [29] and a target slump of at least $50 \mathrm{~mm}$ was adopted while selecting the mixtures. The replacement of sand by waste iron powder reduces the flowability of the mixture due to the elongated nature of the iron particulates as contrasted with the rounded sand particles. This increases the specific surface area and points of contact resulting in a higher yield stress for mixtures containing higher amounts of iron particulates. Beyond $20 \%$ sand replacement by volume, the target slump is not met which is the reason for limiting the dynamic performance evaluation to mixtures containing up to $20 \%$ waste iron powder as sand-replacement. $50 \mathrm{~mm}$ cubes were cast for compressive strength evaluation while cylindrical discs of 1.5-inch diameter and 0.6-inch length (L/D ratio of 0.4 [30,31]) were used for dynamic testing. Four replicate specimens were prepared for each test. The curing of samples was done as per ASTM C109 [32]. The samples were demolded after one day and kept in moist environment $(\mathrm{RH}>98 \%)$ at a temperature of $23 \pm 2{ }^{\circ} \mathrm{C}$ for 28 days before testing. For microstructural evaluation, companion paste samples were prepared and kept in sealed condition.

\subsection{Scanning electron microscopy (SEM) for microstructural evaluation}

For microstructural evaluation, $10 \times 10 \mathrm{~mm}$ cube samples were cut using a diamond saw. After cutting, ultrasonic cleaning ensured removal of debris. The samples were then epoxy-encapsulated and vacuumsaturated. Afterwards, several grinding and polishing steps were followed to achieve smoothness of the surface. The final polishing was done using $0.04 \mu \mathrm{m}$ colloidal silica suspension. Field emission environmental scanning electron microscope (FESEM) was used to image the samples for microstructural evaluation.

\subsection{Quasi-static Compressive Strength Test}

Quasi-static compressive strength test was performed according to ASTM C 109 standard test procedure [32]. The test is performed on 2-inch cube mortar specimens. Four replicate specimens were used for each mixture to obtain the quasi-static compressive strengths. 


\subsection{Split Hopkinson Pressure Bar Test}

Dynamic characterization of particulate-reinforced mortars was performed using Split Hopkinson Pressure Bar (SHPB) setup as show in Figure 2. The SHPB setup consists of striker bar, incident bar and transmitter bar. Diameter for both bar incident and transmitter bars was $0.05 \mathrm{~m}(2$ "). The specimen (1.5" diameter and 0.6" thickness) was sandwiched between the incident and transmitter bars as shown in Figure 2. The striker bar is first launched towards the incident bar at a predefined velocity and it generates a compressive stress pulse in the incident bar which propagates towards the specimen. When the stress wave reaches the incident bar-specimen interface, it is partly reflected back to the incident bar and partly transmitted to the specimen. While the amplitude of the transmitted pulse is related to the stress in the specimen, the amplitude of the reflected pulse is related to the strain rate [33]. The specimen can be subjected to various strain rates by changing the length of striker bars. In the paper the specimens were subjected to strain rates $100 \mathrm{~s}^{-1}$ and $250 \mathrm{~s}^{-1}$. The stress-strain response for varying applied strain rates can be obtained from the incident and transmitter bar strain signals using one-dimensional wave analysis. The analysis procedure is adequately detailed in the literature $[33,34]$.

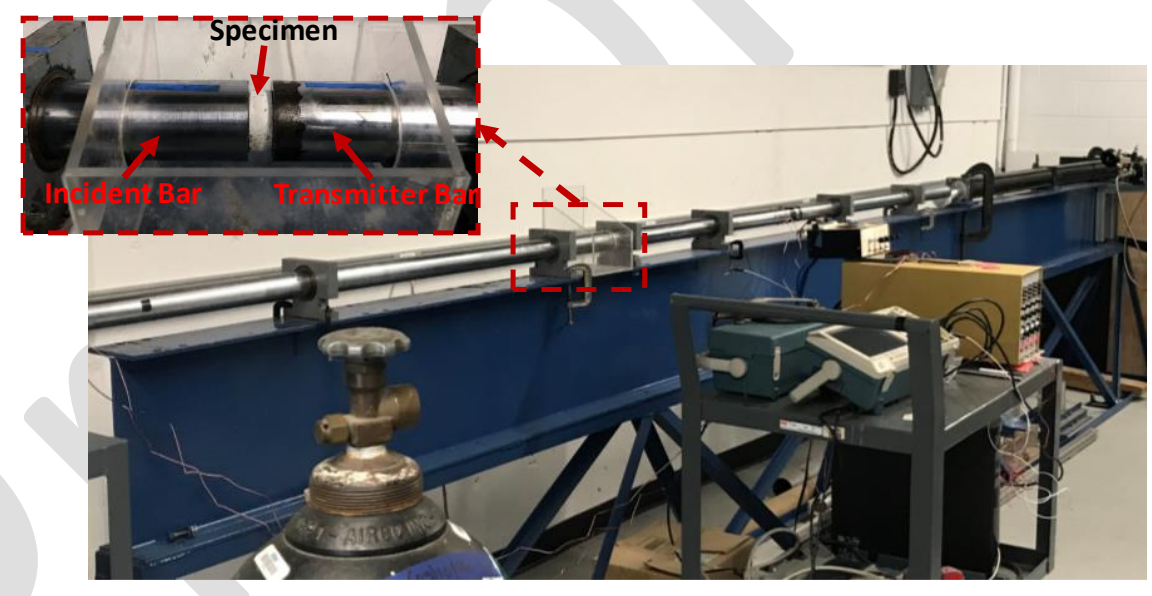

Figure 2. SHPB Test Setup

\section{RESULTS AND DISCUSSIONS}

\subsection{Microstructural evaluations}

Microstructural analysis was carried out after 28 days of hydration to evaluate the distribution of iron particulates in the matrix. Figure 3 shows the SEM image of the microstructure under backscattered electron (BSE) mode. Distribution of bright (high density) elongated iron particulates in the matrix (gray) can be clearly observed. The presence of elongated stiff iron particulates, shown to improve quasi-static 
crack growth resistance $[24,25,35,36]$, are likely to improve the mechanical behavior of mortars under high strain rates which is explored in detail in this paper.

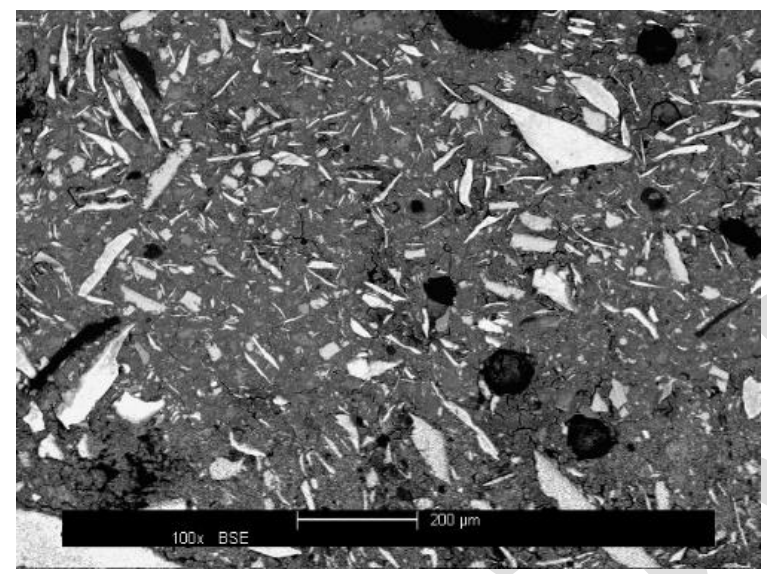

Figure 3: BSE images of iron powder ( $20 \%$ by volume) dispersed in hardened cement paste matrix

\subsection{Quasi-static compressive strength of particulate-reinforced mortars}

Figure 4 shows the quasi-static 28-day compressive strengths of mortars. The mortars show significant increase in compressive strength with increase in iron powder content. This can likely be attributed to the presence of elongated iron particulates (as partial replacement of sand) that act as micro-reinforcement in the system thereby improving the mechanical behavior. While this section reports the quasi-static compressive strengths of the mortars, the forthcoming section elucidates the effect of iron particulates on the dynamic compressive behavior of the same.

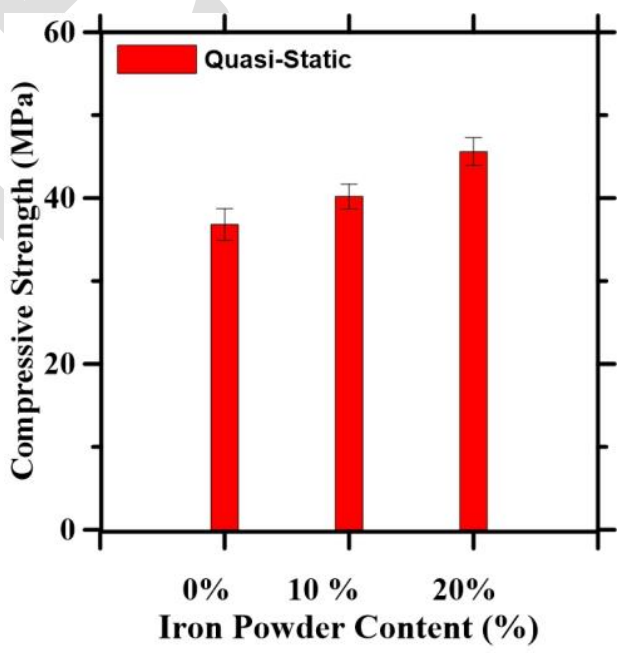

Figure 4: Quasi-static compressive strength of mortars 


\subsection{Dynamic compressive response}

In this section, the dynamic compressive behavior of metallic particulate-reinforced mortars is evaluated using SHPB test results. The SHPB tests were performed for all the materials under two different strain rates (100/s and 250/s). Figures 5 (a) and (b) show the compressive stress-strain responses of the mortars under strain rates of $100 / \mathrm{s}$ and $250 / \mathrm{s}$ respectively. For both the strain rates, the peak compressive stress increases with increase in iron powder content, which is in line with the findings from quasi-static compressive strengths (Figure 4). The strength-enhancement with increasing iron powder content can be attributed to the presence of elongated iron particulates in the matrix acting as micro-reinforcements as explained earlier. The figures $5(a)$ and (b) show slight increase in the peak stress when the strain rate is increased from $100 / \mathrm{s}$ to $250 / \mathrm{s}$ although the enhancement is not as pronounced as observed when the strain rate was increased from the quasi-static condition to a strain rate of 100/s. Similar strain ratedependent behavior for cementitious materials are reported in [27]. The figures also indicate that the area under the stress-strain curve, a measure of energy absorption capacity, increases with the rise in iron powder content implying toughness-enhancement.
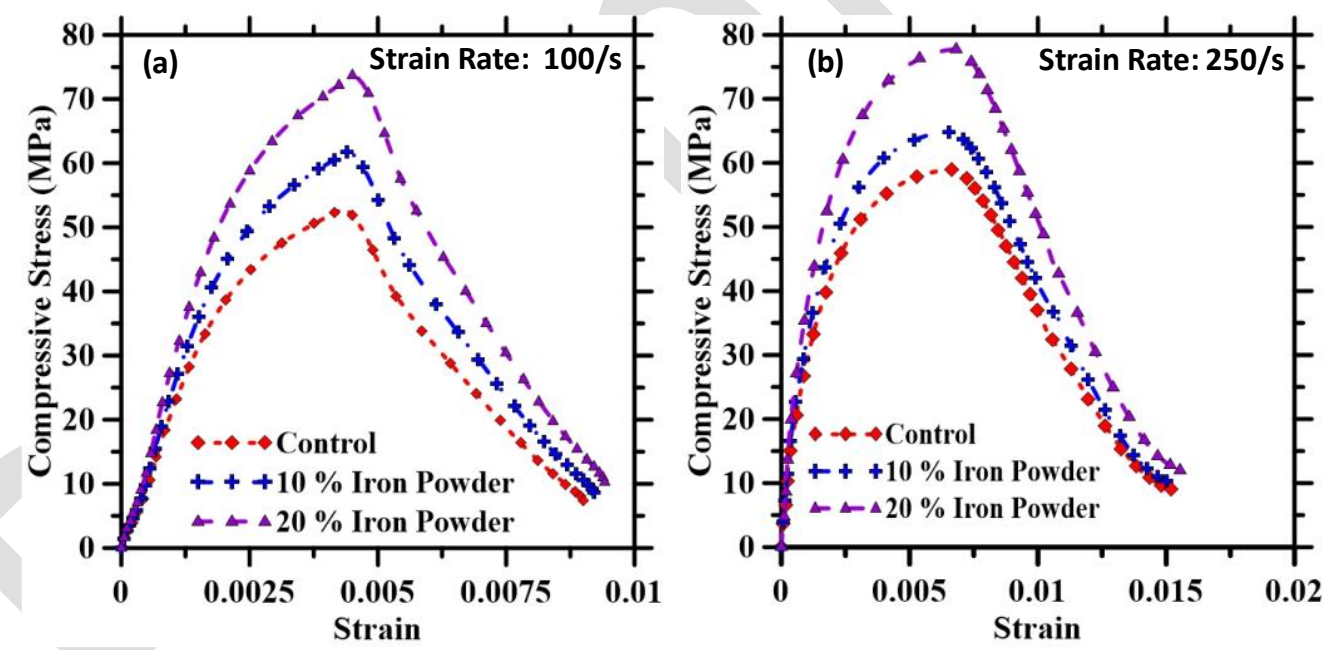

Figure 5: Representative stress-strain response of iron particulate-reinforced mortars corresponding to strain rates (a) $100 / \mathrm{s}$ and (b) $250 / \mathrm{s}$

Figure 6(a) shows the strain rate-dependent compressive strengths of mortars. The dynamic increase factors (DIF), the ratio of dynamic compressive strength to the quasi-static strength, are also reported in Figure $6(\mathrm{~b})$. While quasi-static evaluations show $9 \%$ and $24 \%$ increase in compressive strength with incorporation of $10 \%$ and $20 \%$ iron powder in mortar respectively, more than $10-17 \%$ and $32-40 \%$ strength-enhancement is observed for the mortar mixtures with $10 \%$ and $20 \%$ iron powder respectively 
under higher strain rates. This can be attributed to the micro-reinforcement feature of elongated iron particulates that is likely to offer increased resistance to crack growth through various mechanisms such as crack deflection and crack bridging $[24,25,35,36]$. Further detailed microstructural investigations on the fractured surfaces are needed to be performed to confirm this. Furthermore, macro-scale failure modes in such particulate-reinforced systems are needed to be explored in future involving digital image correlation (DIC) to evaluate the crack propagation mechanisms under high strain rates. The strengthenhancement trends are also reflected in the dynamic increase factors (DIF), reported in Figure 6(b) which shows significant increase in the DIF with increasing iron powder content. The static and dynamic compressive strengths as well as DIFs are also sown in Table 2 for clarity. Figure 6(c) reports the dynamic energy absorption capacities of mortars with varying iron powder content. While an increase of about $15 \%$ in energy absorption capacity was observed from quasi-static responses for the mortars incorporating $20 \%$ iron powder as cement-replacement [24], the dynamic compressive responses exhibit about $35 \%$ enhancement (for a strain rate of $250 / \mathrm{s}$ ) in energy absorption capacity for $20 \%$ iron powder case. These results suggest significantly improved performance of iron powder-modified mortars as compared to traditional control mortars under high strain rates.
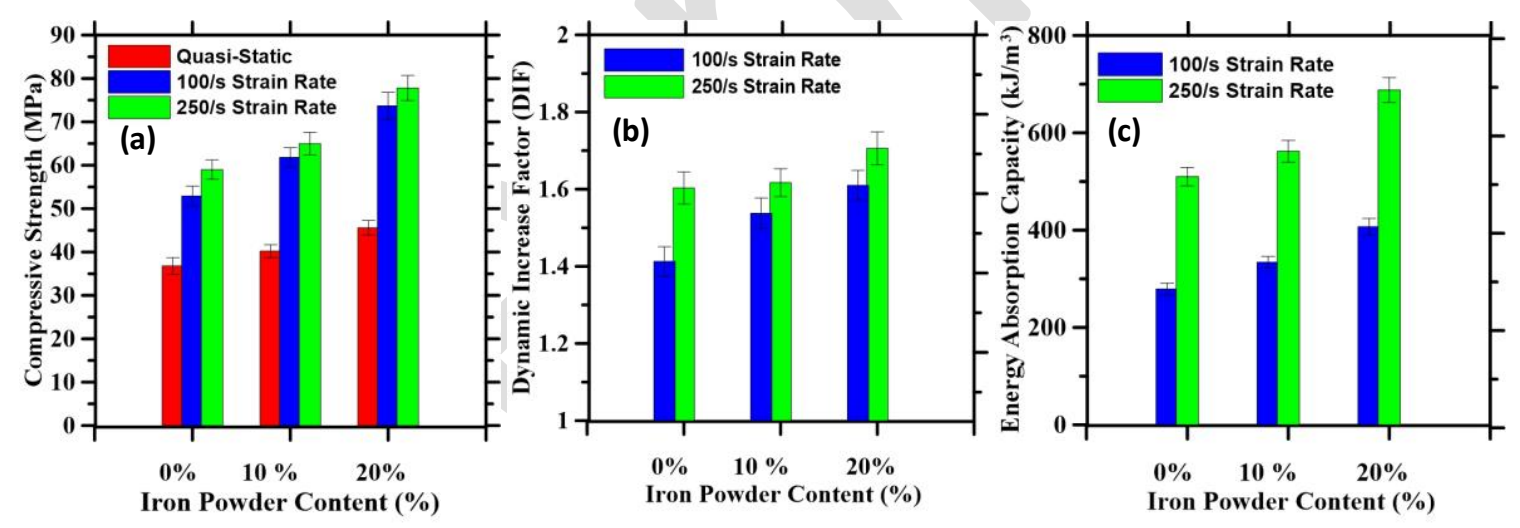

Figure 6: (a) Quasi-static and dynamic compressive strength, (b) dynamic increase factor and (c) energy absorption capacity of mortars 
Table 2: Static and dynamic compressive strengths and dynamic increase factors

\begin{tabular}{|c|c|c|c|c|c|}
\hline \multirow{2}{*}{$\begin{array}{c}\text { Iron Powder } \\
\text { Dosage }\end{array}$} & Static & \multicolumn{3}{|c|}{ Dynamic } \\
\cline { 2 - 6 } & $10^{\wedge}-3 /$ s Strain Rate & \multicolumn{2}{|c|}{$100 / \mathrm{s}$ Strain Rate } & \multicolumn{2}{c|}{$250 / \mathrm{s}$ Strain Rate } \\
\cline { 2 - 6 } & Strength (MPa) & Strength (MPa) & DIF & Strength (MPa) & DIF \\
\hline 0 & $36.8 \pm 1.93$ & $52.9 \pm 2.28$ & 1.41 & $59 \pm 2.24$ & 1.60 \\
\hline 10 & $40.2 \pm 1.49$ & $61.8 \pm 2.23$ & 1.53 & $65 \pm 2.6$ & 1.61 \\
\hline 20 & $45.6 \pm 1.69$ & $73.7 \pm 3.14$ & 1.61 & $77.8 \pm 2.89$ & 1.70 \\
\hline
\end{tabular}

\subsection{Multiscale numerical simulations for dynamic response of particulate-reinforced mortars}

While the previous section evaluated experimental dynamic compressive behavior of mortars, this section focusses on development of a multi-scale simulation-based predictive tool for dynamic compressive constitutive response of such composites in a continuum micromechanics framework. To capture the complex heterogeneity of cementitious systems, the numerical homogenization is carried out at multiple length scales to obtain strain rate-dependent homogenized dynamic compressive response for particulate-reinforced mortars that can be validated with the experimental observations, reported in the previous section. The geometrical configurations of various phases are represented at every length scale using representative unit cells. The following sub-sections elaborate the simulation framework and its application towards prediction of dynamic compressive constitutive response of iron powder modified mortars. The tools for the multiscale numerical simulation include python scripts for microstructure generation, material property assignment and analysis by ABAQUS ${ }^{\mathrm{TM}}$ solver followed by volume averaging post-processor in MATLAB script.

\subsubsection{Numerical Simulation Framework to predict effective dynamic constitutive response}

The influence of particulate reinforcements on the dynamic compressive behavior of mortars is elucidated using the framework detailed in this section. The representative unit cells are first generated based on microstructural features of the material. Thereafter, boundary conditions are applied and the unit cells are meshed. Finally, uniaxial strain is applied at a certain rate to obtain stress-response. Thus, the effective constitutive response of such systems are acquired. The strain rate-dependent damage in the post-peak regime is efficiently integrated into the simulation approach. A schematic representation of the numerical 
homogenization approach is shown in Figure 7. The various components of the approach are elaborated in the forthcoming sub-sections for a comprehensive understanding.

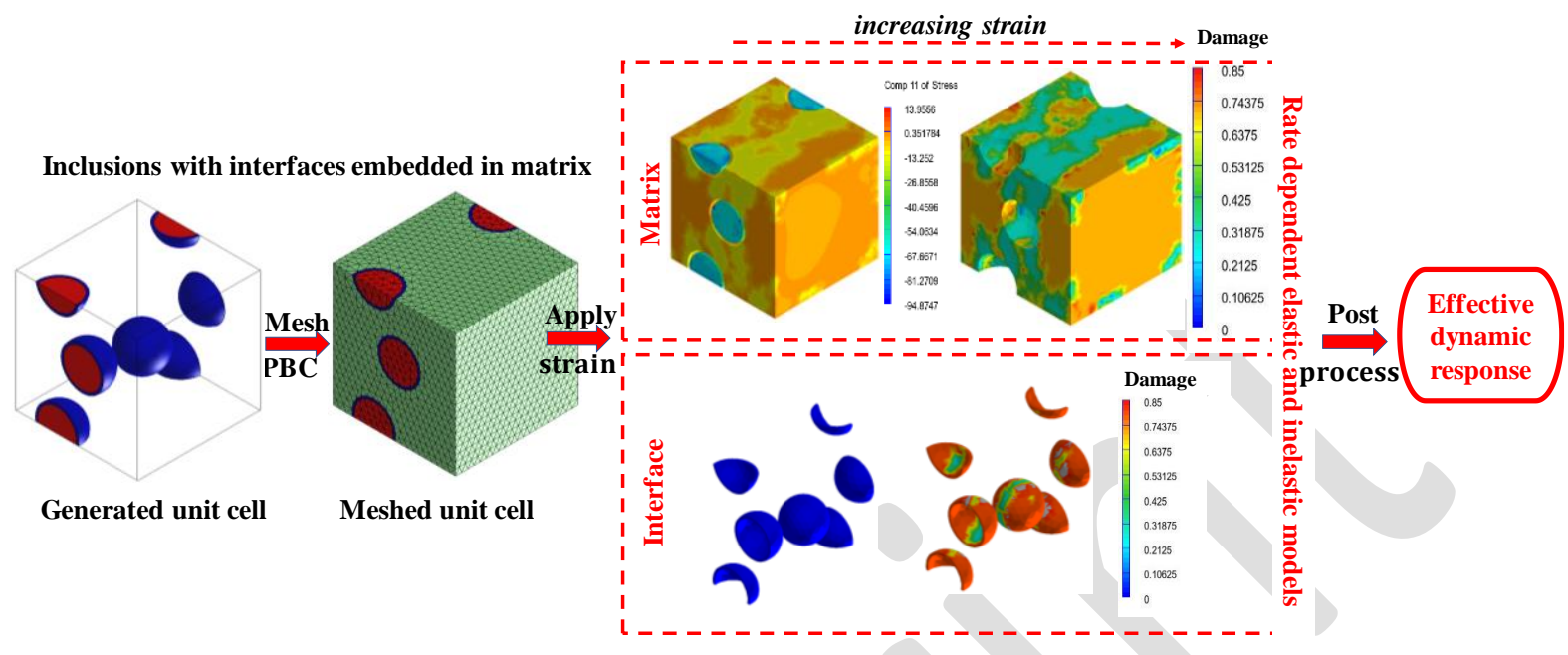

Figure 7: A schematic diagram representing the numerical homogenization methodology

\subsubsection{Unit cell generation}

The Lubachhevsky-Stillinger algorithm $[39,40]$ is used to generate the unit cells. A hard particle contact model is implemented and particle overlaps are restricted in this algorithm. The algorithm has been rigorously implemented in $[25,41-44]$ towards unit cell generation and adequately detailed in $[39,40]$.

\subsubsection{Boundary conditions}

Periodic boundary conditions (PBC) $[41,43,45]$ are applied on the meshed unit cells. A python script handles the meshing. The boundaries of the neighboring unit cells maintain a displacement and traction continuity owing to PBC implementation. Such BCs have been applied successfully to random heterogeneous systems subjected to FE analyses [42-44,46]. Periodic boundary conditions facilitate faster convergence even with smaller size of unit cells owing to higher computational efficiency [41]. PBCs are elaborated in $[41,42,47]$.

\subsubsection{Homogenization of constitutive response}

The meshed RVE is subjected to uniaxial compressive strain at different strain-rates to simulate a displacement-controlled test scenario. The pre-peak homogenized response of the composite is characterized by the dynamic modulus of the matrix. The dynamic modulus as a function of strain rate is expressed as shown in Equation 1 [27]. 


$$
E=\left[C_{1}+C_{2}\left(\frac{\dot{\varepsilon}_{d}}{\dot{\varepsilon}_{s}}\right)^{C_{3}}\right]
$$

Where $C_{1}, C_{2}$ and $C_{3}$ are material parameters; $\dot{\varepsilon}_{d}$ and $\dot{\varepsilon}_{s}$ are dynamic and quasi-static strain rates $\left(\dot{\varepsilon}_{s}=\right.$ $3 \times 10^{-6}$ ). While the rate dependent dynamic modulus governs the elastic constitutive response, the inelastic response is governed by the rate-dependent damage as discussed in the forthcoming subsection.

\subsubsection{Rate-dependent damage}

A strain rate-dependent damage model $[27,28]$ is adopted in the current study. A damage variable $D(\varepsilon, \dot{\varepsilon})$ that lies between 0 and 1 characterizes the stiffness-loss for the damaged material as shown in Equation 2. The damage variable $D$ is a function of strain $\varepsilon$ and its temporal derivative $\dot{\varepsilon}[27,28]$.

$$
\sigma_{d}(\varepsilon, \dot{\varepsilon})=(1-D)[\sigma(\varepsilon, \dot{\varepsilon})]
$$

Where $\sigma_{d}(\varepsilon, \dot{\varepsilon})$ and $\sigma(\varepsilon, \dot{\varepsilon})$ are the stresses for damaged and un-damaged materials respectively. A nonlinear strain rate-dependent damage evolution model for dynamic compressive response of cementitious materials, given in Equation $3[27,28]$, is adopted in this study.

$$
\dot{D}=c_{5} \dot{\varepsilon}+c_{4} \dot{\varepsilon}^{\lambda}
$$

Where $c_{4}, c_{5}$ and $\lambda$ are material constants. Considering a constant strain rate, the time integral of Equation 3 gives the damage parameter $D$ as shown in Equation 4.

$$
D=\left(c_{5}+c_{4} \dot{\varepsilon}^{\xi}\right) \varepsilon+c_{6}
$$

Where $\xi=\lambda-1$ and $c_{2}$ is an integration constant. Subjecting Equation 4 to an initial boundary condition $\left.D\right|_{\varepsilon=0}=0$ yields $c_{6}=0$ resulting in Equation 5 .

$$
D=\left(c_{5}+c_{4} \dot{\varepsilon}^{\xi}\right) \varepsilon ; \varepsilon>\varepsilon_{D_{0}}
$$

The values of $c_{5}, c_{4}$ and $\xi$ are material constants. The current framework implements the damage characterized by Equation 5 at a strain beyond the damage initiation threshold $\varepsilon_{D_{0}}$. The strain ratedependent damage model is implemented here using an user defined subroutine in ABAQUS ${ }^{\mathrm{TM}}$.

\subsubsection{Post-processing}

The unit cell is subjected to uniaxial strain at various strain rates and the analysis is implemented through a python script in ABAQUS ${ }^{\text {Tm }}$ solver to obtain the strain rate-dependent compressive response of the 
composite. A post-processing module coded in $M A T L A B^{\circledR}$ computes the volume-averaged responses of unit cells to obtain composite constitutive response that includes both elastic (pre-peak) and inelastic regimes (post-peak). The forthcoming section applies the above-mentioned numerical simulation approach to obtain strain rate-dependent constitutive response of iron powder modified mortars.

\subsubsection{Numerical Simulation at multiple scale lengths for dynamic compressive response}

The analysis is carried out at two different scales as shown in Figure 8 (The mixture corresponds to a representative sample with $10 \%$ waste iron powder). The median particle size of sand and iron powder, adopted in this numerical simulation, are $600 \mu \mathrm{m}$ and $19 \mu \mathrm{m}$ respectively (refer to section 2.1). Average length to diameter ratio of 12 , obtained from image analysis of several backscattered micrographs (Figure 3 ), is adopted towards unit cell generation. In the numerical simulation framework, the iron particulates are first homogenized into the HCP matrix (Figure 8(a)) to obtain effective strain rate-dependent compressive constitutive response of iron powder-modified HCP. The homogenized responses for iron powder-modified HCP, thus obtained, are used as matrix properties in the mortar scale where the sand inclusions are homogenized into the iron powder-modified HCP matrix to obtain effective strain ratedependent compressive constitutive response of iron powder-incorporated mortars (Figure 8(b)). While the interfaces between the iron particulates and HCP matrix are not considered in this study due to lack of data [48], the presence of interfacial transitions zones (ITZ) at the sand-matrix interfaces and the influence of interface damage at the ITZ are efficiently incorporated in this study. The thickness of ITZ is considered to be $20 \mu \mathrm{m}[49,50]$. In both the length scales, linear elastic behavior of inclusions (sand and iron particles) is considered. Similar approach is successfully incorporated in [41,48,51,52]. The sizes of the unit cells (see Figure 8) are determined from a sensitivity study. 2D unit cells are implemented as a trade-off between computational demand and efficiency in the current study. Such 2D representative areas have been adopted in $[43,53]$ towards damage prediction in quasi-brittle systems. The constitutive responses, obtained from numerical homogenization, enable identification of peak strengths, DIF and absorbed energy of composite mortars which are validated with SHPB experimental observations. 


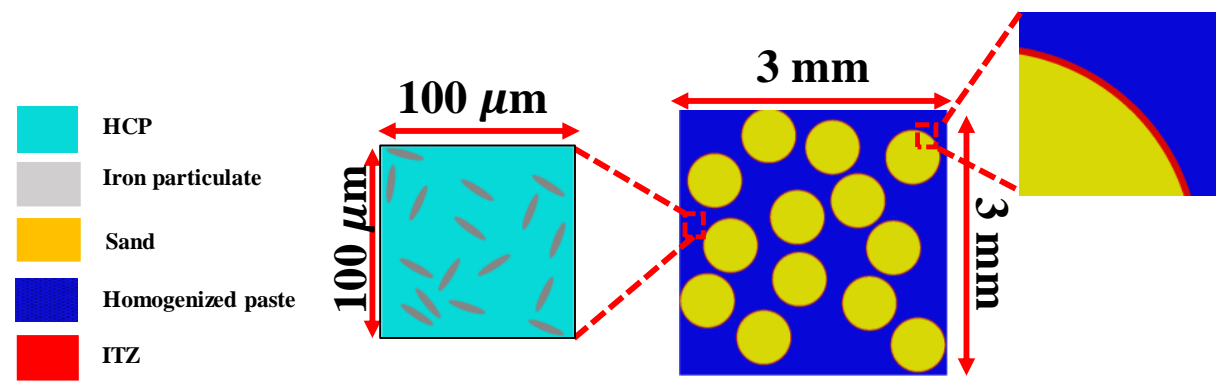

(a)

(b)

Figure 8: Generated unit cells corresponding to: (a) micro-scale: HCP matrix and 10\% iron particulates;

(b) meso scale: modified HCP matrix and sand inclusions

The following sub-sections elucidate numerical homogenization at the paste and mortar scales to obtain the effective strain rate-dependent compressive constitutive responses of the particulate-reinforced mortars.

\subsubsection{Effective constitutive response}

The numerical homogenization results obtained from multi-scale analysis are presented in this section. The periodically bounded meshed unit cell (see Figure 8(a) for micro-scale) is subjected to an uniaxial compressive strain along $\mathrm{X}$ direction with a specific strain rate. The material parameters for control HCP, reported in Table 3, are adopted for the matrices of all the mixtures at this scale with various contents of iron powder. While the quasi-static Young's modulus is considered as $200 \mathrm{GPa}[25,41]$ for iron particulates, the strain rate-dependent elastic response of iron particulates is characterized by gains in moduli of $60 \%$ and $80 \%$ for strain rates of $100 / \mathrm{s}$ and $250 / \mathrm{s}$ respectively as reported in [54]. A Poisson's ratio equaling 0.3 is adopted for iron particles whereas a Poisson's ratio equaling 0.2 is considered for all other phases in this study. Insignificant changes in results have been reported for the range of Poisson's ratio considered in this study $[46,55]$.

Table 3: Material parameters for HCP $[27,56]$

\begin{tabular}{|c|c|c|c|c|c|c|}
\hline$C_{1}$ & $C_{2}$ & $C_{3}$ & $\xi$ & $C_{5}$ & $C_{4}$ & $\varepsilon_{D_{0}}$ \\
\hline 5064.1 & 4.71 & 1.70 & 0.487 & 0.657 & 0.019 & 0.001 \\
\hline
\end{tabular}

The simulation is performed using ABAQUS ${ }^{\mathrm{TM}}$ and progressive matrix damage is obtained, as shown in Figure 9 for a strain rate of 100/s. 


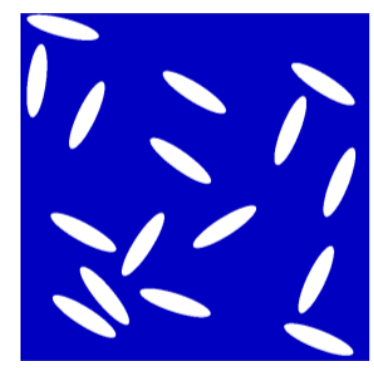

(a)

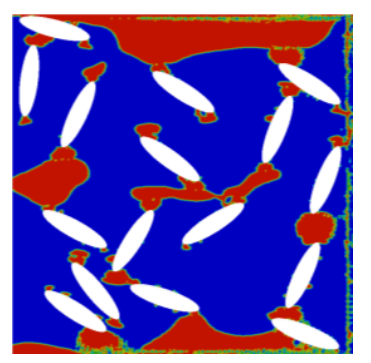

(b)

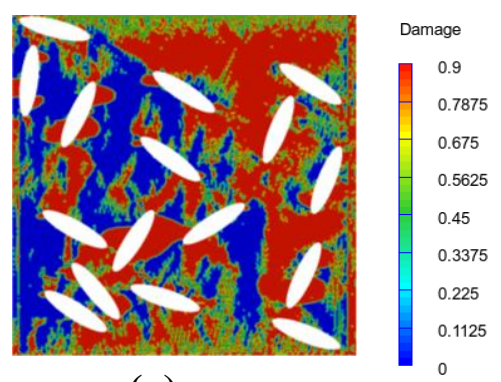

(c)

Figure 9: Progressive damage with increasing strain for a strain rate of $100 / \mathrm{s}$ for the mortar mixture with $10 \%$ iron powder content under strain of: (a) 0 , (b) 0.0035 and (c) 0.006 .

The Figures 9(a), (b) and (c) show the progressive damage states corresponding to uniaxial strains of zero, 0.0035 and 0.006 respectively. The progressive damage in the matrix can be observed clearly in Figures 9(b) and (c). The homogenized response for iron powder-incorporated HCP, thus obtained, for various dosage of iron powder are used to extract all the material parameters for iron powder incorporated HCP mixtures and the extracted parameters are reported in Table 4.

Table 4: Extracted material parameters for homogenized iron powder-incorporated HCP

\begin{tabular}{|c|c|c|c|c|c|c|c|}
\hline Iron powder (\%) & $C_{1}$ & $C_{2}$ & $C_{3}$ & $\xi$ & $C_{5}$ & $C_{4}$ & $\varepsilon_{D_{0}}$ \\
\hline $10 \%$ & 6735 & 4.73 & 1.696 & 0.498 & 0.701 & 0.0131 & 0.0013 \\
\hline $20 \%$ & 13450 & 4.75 & 1.694 & 0.512 & 0.753 & 0.0148 & 0.0015 \\
\hline
\end{tabular}

The material parameters for iron powder-incorporated HCP mixtures are implemented to define the material model for the matrix in the mortar scale (Figure 8(b). The dynamic modulus for sand-HCP interface elements is considered $40 \%$ of the dynamic modulus of the matrix $[49,57]$. To identify the cracking strain for damage initiation at the sand-HCP interface (ITZ) elements, an inverse analysis procedure is followed. The inverse analysis approach involves generation of a representative volume element (RVE) containing 50\% volume of sand embedded in the HCP matrix along with $20 \mu \mathrm{m}$ thick ITZ around the sand inclusions. The RVE is subjected to a quasi-static uniaxial strain of $0.25 \varepsilon_{D_{0}}^{M}$ (where $\varepsilon_{D_{0}}^{M}$ is the cracking strain for the matrix considered 0.001 for HCP $[56,58])$. The interfacial debonding at the ITZ has been reported [56] to be initiated at an externally applied uniaxial strain of $0.25 \varepsilon_{D_{0}}^{M}$ in the mortars. Hence, the maximum strain at the interface elements under an externally applied strain of $0.25 \varepsilon_{D_{0}}^{M}$ can be considered as the cracking strain at the ITZ $\left(\varepsilon_{D_{0}}^{I T Z}\right)$. This procedure yields the limiting strain as 0.0006 for the ITZ that serves as the damage initiation criteria for such elements. The damage propagates in the ITZ 
as per the strain rate-dependent damage theory, explained earlier. All the other material parameters except, the dynamic modulus and $\varepsilon_{D_{0}}^{I T Z}$ are considered to be same as that of HCP due to lack of data. The strain rate-dependent elastic response of sand inclusions is characterized in terms of the secant modulus which follows a linear relation with the logarithmic strain rate [59]. Here, gains of $40 \%$ and $60 \%$ in modulus is considered as compared to quasi-static conditions for strain rates of 100/s and 250/s respectively [59]. Thus, the quasi-static modulus for sand is taken as $70 \mathrm{GPa}[25,41,43]$ and the rate dependent moduli are obtained from the respective gains.

Figure 10 presents the progressive damage in the interface and the matrix at the mortar scale for the mortar mixture with $10 \%$ iron powder content for strain rate of 100/s. While Figures $10(a-1),(a-2),(a-3)$ and (a-4) correspond to the interface damage, the Figures $10(b-1),(b-2),(b-3)$ and (b-4) depict the matrix damage. Figures 10(a-1) and 9(b-1) correspond to undeformed configuration whereas Figures $10(a-2)$ and $9(b-2)$ correspond to a strain of 0.0015 . The matrix and interface damage configurations at a strain of 0.0055 are shown in Figures 10(a-3) and (b-3) respectively. Figures 10(a-4) and (b-4) exhibit the damage at the interfaces and matrix damage respectively corresponding to a compressive strain of 0.0075 . The interface damage, as depicted in the progressive damage for the meso-scale mortars, commences at a lower strain than the peak global strain. It propagates with increasing global strain until the matrix stresses exceed the compressive strength. Thereafter, matrix damage initiates thereby yielding the global postpeak response.

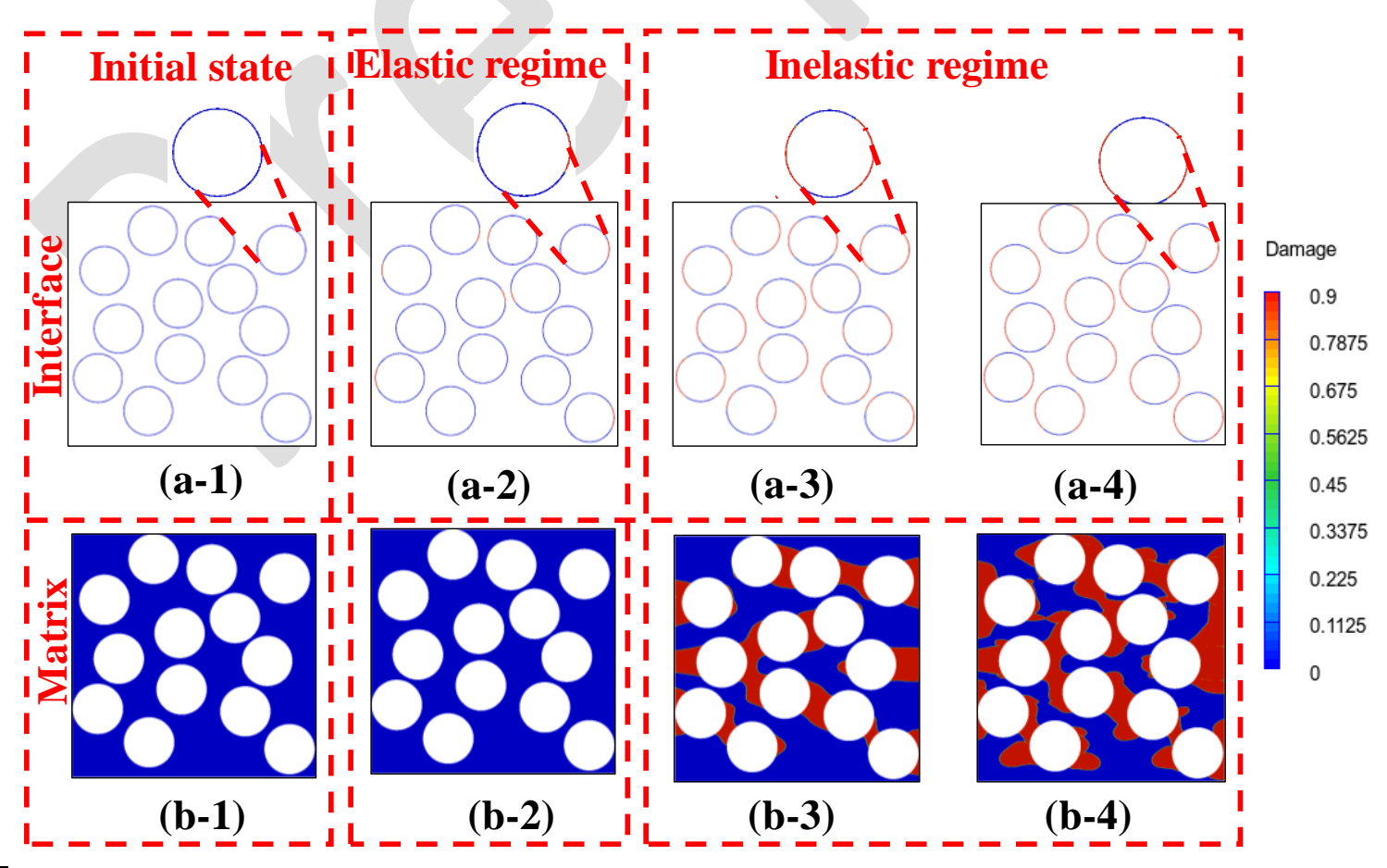


Figure 10: Progressive damage with strain for a strain rate of $100 / \mathrm{s}$ at (a) interface and (b) matrix in iron powder ( $10 \%$ by sand replacement) incorporated mortar corresponding to applied strains of (a-1)\&(b-1)

$$
0 \text { (undeformed), (a-2)\&(b-2) } 0.0015,(a-3) \&(b-3) \quad 0.0055 \text { and (a-4)\&(b-4) } 0.0075 \text {. }
$$

Figures $11(a)$ and (b) show the simulated strain rate-dependent compressive constitutive response for mortars corresponding to strain rate of $100 / \mathrm{s}$ and $250 / \mathrm{s}$ respectively. With increasing strain rate, the dynamic modulus increases (see Equation 1) and an enhancement in the simulated compressive strength is observed for both the control and iron powder incorporated mortars. The compressive response is also enhanced with increasing dosage of iron powder for both the strain rates which is in line with the experimental observations. With a view to evaluate the predictive capability of the multiscale numerical simulation approach presented herein, the forthcoming section depicts correlations between the simulated responses and experimental observations.
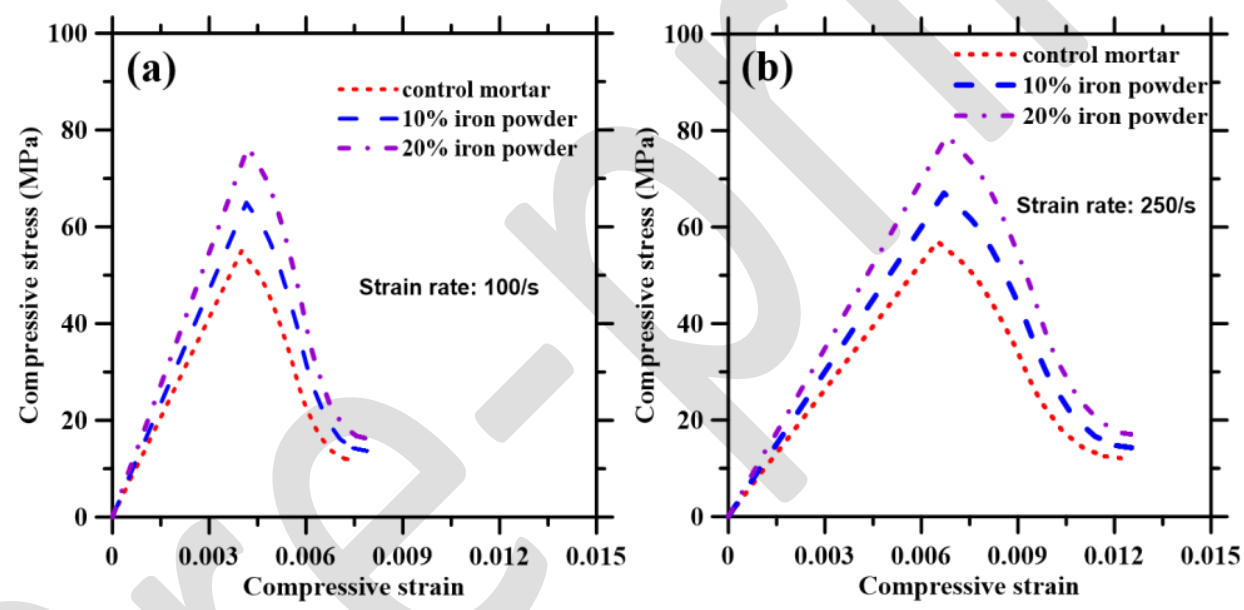

Figure 11: Simulated dynamic constitutive response for iron-particulate (varying dosage) reinforced mortars for strain rates of (a)100/s and (b)250/s

\subsubsection{Comparison between the simulated and experimental responses}

This section presents a comparative evaluation between the simulated and experimental strain-rate dependent compressive responses. While Figure 12(a) reports the correlation between simulated and experimental compressive strengths, Figure 12(b) exhibits the absorbed energies for all the mortar mixtures considered here. A close correlation between simulated and experimental strengths (Figure 12(a)) suggests the applicability of such a numerical framework to inclusion modified heterogenous systems towards effective dynamic strength prediction whereas a good agreement between the experimental and simulated absorbed energies (Figure 12(b)) confirms the efficacy of the current 
numerical simulation procedure towards prediction of strain rate-dependent post-peak compressive responses in the particulate-reinforced mortars.
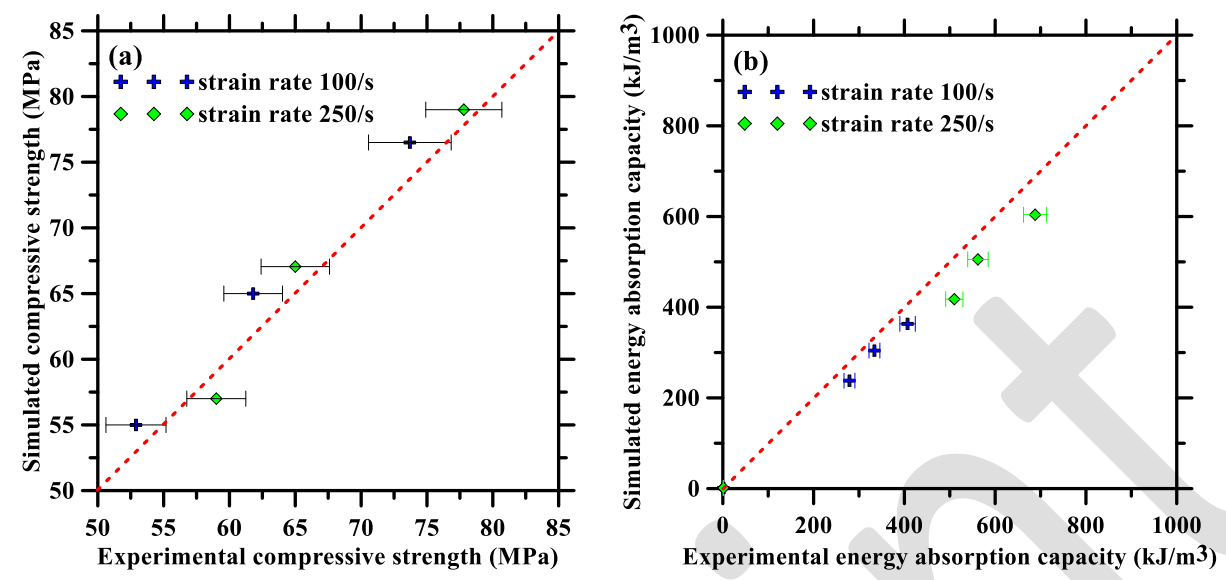

Figure 12: A comparison between experimentally obtained and simulated: (a) compressive strengths and (b) energy absorption capacities for mortars with varying dosage of iron powder

\section{CONCLUSIONS}

This paper explores the influence of waste metallic iron particulates on the dynamic compressive response of mortars under high strain rates. The strain rate-dependent dynamic compressive responses of waste iron powder-incorporated mortars were evaluated using SHPB tests. The SHPB results indicate significant enhancement in compressive strength and energy absorption capacity at high strain rates with increasing iron powder content attributable to presence of elongated iron particulates that act as microreinforcement in the mortars. The elongated iron particulates enhance the mechanical response through various probable toughening mechanisms such as crack bridging and crack deflections which needs further investigations for confirmation involving evaluation of strain/displacement fields in the specimen using DIC and microstructural observations on fractured surfaces. Besides performance-enhancement, use of waste iron powder (which is otherwise landfilled) is environmentally beneficial from solid waste disposal point of view. In this study, the dosage of iron powder higher than $20 \%$ sand-replacement by volume has not been considered since such mortar mixtures with higher dosage of iron powder do not exhibit satisfactory rheological behavior. The use of superplasticizers on such mortar mixtures with highvolume iron powder content is likely to influence the early-age rheological behavior and later age mechanical behavior which needs further investigations in future for more insights. While the experimental observations using SHPB tests showed significant enhancements in dynamic compressive responses with incorporation of iron powder as sand-replacement, the multiscale numerical simulation 
methodology embodies an efficient predictive tool that helps microstructure-guided design of these particulate-reinforced mortars for efficient dynamic performance. The numerical simulation approach performs numerical homogenization at two different length scales so as to obtain the macro-scale dynamic compressive response of the mortars. The numerical homogenization at every length scale involves generation of representative unit cell from known microstructural features of the materials, application of appropriate boundary conditions and implementation of a strain-rate dependent damage model in a continuum micromechanics framework to obtain effective strain rate-dependent dynamic constitutive response of the composites. The simulated dynamic compressive strength and energy absorption capacity, thus obtained for iron particulate-reinforced mortars for various iron powder contents, correlate well with the experimental observations thereby depicting the efficacy of the multiscale approach. Thus, the methodology successfully integrates different length scales and yields a micro-macro link for the particulate-reinforced mortars under high strain rates facilitating microstructureguided material design of such composites for efficient dynamic compressive performance under high strain rates.

\section{ACKNOWLEDGEMENT}

The study was carried out in the Laboratory of Advanced Materials in Civil Infrastructure (LAMCI) and Dynamic Photomechanics Laboratory (DPML) at the University of Rhode Island (URI). The supports that have made these laboratories possible are acknowledged. The authors acknowledge Iron Shell LLC for providing the iron powder.

\section{REFERENCES}

[1] S.P. Shah, S.E. Swartz, C. Ouyang, Fracture Mechanics of Concrete: Applications of Fracture Mechanics to Concrete, Rock and Other Quasi-Brittle Materials, John Wiley \& Sons, 1995.

[2] N. Banthia, M. Sappakittipakorn, Toughness enhancement in steel fiber reinforced concrete through fiber hybridization, Cem. Concr. Res. 37 (2007) 1366-1372.

[3] H. Su, J. Xu, Dynamic compressive behavior of ceramic fiber reinforced concrete under impact load, Constr. Build. Mater. 45 (2013) 306-313.

[4] Suaris Wimal, Shah Surendra P., Constitutive Model for Dynamic Loading of Concrete, J. Struct. Eng. 111 (1985) 563-576. doi:10.1061/(ASCE)0733-9445(1985)111:3(563).

[5] Z.L. Wang, Z.M. Shi, J.G. Wang, On the strength and toughness properties of SFRC under static-dynamic compression, Compos. Part B Eng. 42 (2011) 1285-1290.

[6] Z. Rong, W. Sun, Y. Zhang, Dynamic compression behavior of ultra-high performance cement based composites, Int. J. Impact Eng. 37 (2010) 515-520.

[7] S.G. Millard, T.C.K. Molyneaux, S.J. Barnett, X. Gao, Dynamic enhancement of blastresistant ultra high performance fibre-reinforced concrete under flexural and shear loading, Int. J. Impact Eng. 37 (2010) 405-413. 
[8] G. Yang, X. Chen, W. Xuan, Y. Chen, Dynamic compressive and splitting tensile properties of concrete containing recycled tyre rubber under high strain rates, Sādhanā. 43 (2018) 178. doi:10.1007/s12046-018-0944-5.

[9] Lok T. S., Zhao P. J., Impact Response of Steel Fiber-Reinforced Concrete Using a Split Hopkinson Pressure Bar, J. Mater. Civ. Eng. 16 (2004) 54-59.

[10] Z.-L. Wang, Y.-S. Liu, R.F. Shen, Stress-strain relationship of steel fiber-reinforced concrete under dynamic compression, Constr. Build. Mater. 22 (2008) 811-819.

[11] H. Yan, W. Sun, H. Chen, The effect of silica fume and steel fiber on the dynamic mechanical performance of high-strength concrete, Cem. Concr. Res. 29 (1999) 423-426.

[12] Y. Hao, H. Hao, Dynamic compressive behaviour of spiral steel fibre reinforced concrete in split Hopkinson pressure bar tests, Constr. Build. Mater. 48 (2013) 521-532. doi:10.1016/j.conbuildmat.2013.07.022.

[13] M. Nili, V. Afroughsabet, The effects of silica fume and polypropylene fibers on the impact resistance and mechanical properties of concrete, Constr. Build. Mater. 24 (2010) 927-933.

[14] V.T. Giner, F.J. Baeza, S. Ivorra, E. Zornoza, Ó. Galao, Effect of steel and carbon fiber additions on the dynamic properties of concrete containing silica fume, Mater. Des. 34 (2012) 332-339.

[15] B. Riisgaard, T. Ngo, P. Mendis, C. Georgakis, H. Stang, Dynamic Increase Factors for High Performance Concrete in Compression using Split Hopkinson Pressure Bar, Fract. Mech. Concr. Concr. Struct. (2007).

[16] J.W. Tedesco, M.L. Hughes, C.A. Ross, Numerical simulation of high strain rate concrete compression tests, Comput. Struct. 51 (1994) 65-77.

[17] C.A. Ross, Fracture of Concrete at High Strain-Rate, in: S.P. Shah (Ed.), Toughening Mech. Quasi-Brittle Mater., Springer Netherlands, Dordrecht, 1991: pp. 577-596.

[18] V.M.F. Evora, A. Shukla, Fabrication, characterization, and dynamic behavior of polyester/TiO2 nanocomposites, Mater. Sci. Eng. A. 361 (2003) 358-366. doi:10.1016/S0921-5093(03)00536-7.

[19] J.T. Gomez, A. Shukla, A. Sharma, Static and dynamic behavior of concrete and granite in tension with damage, Theor. Appl. Fract. Mech. 36 (2001) 37-49. doi:10.1016/S01678442(01)00054-4.

[20] S.A. Tekalur, A. Shukla, K. Shivakumar, Blast resistance of polyurea based layered composite materials, Compos. Struct. $84 \quad$ (2008) 271-281. doi:10.1016/j.compstruct.2007.08.008.

[21] Chen Xudong, Ge Limei, Chen Chen, Xu Lingyu, Influence of Initial Static Splitting Tensile Loading on Dynamic Compressive Strength of Concrete Cores under High Strain Rates, J. Perform. Constr. Facil. 30 (2016) 06016002. doi:10.1061/(ASCE)CF.1943-5509.0000900.

[22] S. Das, B. Souliman, D. Stone, N. Neithalath, Synthesis and Properties of a Novel Structural Binder Utilizing the Chemistry of Iron Carbonation, ACS Appl. Mater. Interfaces. 6 (2014) 8295-8304.

[23] S. Das, D. Stone, D. Convey, N. Neithalath, Pore- and micro-structural characterization of a novel structural binder based on iron carbonation, Mater. Charact. 98 (2014) 168-179.

[24] S. Das, A. Kizilkanat, N. Neithalath, Crack propagation and strain localization in metallic particulate-reinforced cementitious mortars, Mater. Des. 79 (2015) 15-25.

[25] S. Nayak, N.M.A. Krishnan, S. Das, Fracture response of metallic particulate-reinforced cementitious composites: Insights from experiments and multiscale numerical simulations, Cem. Concr. Compos. 97 (2019) 154-165. 
[26] S. Nayak, A. Kizilkanat, N. Neithalath, S. Das, Experimental and Numerical Investigation of the Fracture Behavior of Particle Reinforced Alkali Activated Slag Mortars, ArXiv190101025 Cond-Mat. (2019). http://arxiv.org/abs/1901.01025 (accessed January 26, 2019).

[27] X. Chen, S. Wu, J. Zhou, Experimental and modeling study of dynamic mechanical properties of cement paste, mortar and concrete, Constr. Build. Mater. 47 (2013) 419-430.

[28] L.-L. Wang, F.-H. Zhou, Z.-J. Sun, Y.-Z. Wang, S.-Q. Shi, Studies on Rate-dependent Macro-damage Evolution of Materials at High Strain Rates, Int. J. Damage Mech. 19 (2010) 805-820.

[29] ASTM C1810 / C1810M - 19: Standard Guide for Comparing Performance of ConcreteMaking Materials Using Mortar Mixtures, ASTM International. doi:10.1520/C1810_C1810M-19.

[30] E.D.H. Davies, S.C. Hunter, The dynamic compression testing of solids by the method of the split Hopkinson pressure bar, J. Mech. Phys. Solids. 11 (1963) 155-179. doi:10.1016/00225096(63)90050-4.

[31] B.A. Gama, S.L. Lopatnikov, J. Gillespie John W., Hopkinson bar experimental technique: A critical review, Appl. Mech. Rev. 57 (2004) 223-250. doi:10.1115/1.1704626.

[32] ASTM C109 / C109M - 16a: Test Method for Compressive Strength of Hydraulic Cement Mortars, ASTM International. doi:10.1520/C0109_C0109M-16A.

[33] S.A. Tekalur, A. Shukla, M. Sadd, K.W. Lee, Mechanical characterization of a bituminous mix under quasi-static and high-strain rate loading, Constr. Build. Mater. 23 (2009) 17951802.

[34] A. Shukla, J.W. Dally, Experimental Solid Mechanics, College House Enterprises, LLC, 2014.

[35] S. Das, A. Hendrix, D. Stone, N. Neithalath, Flexural fracture response of a novel iron carbonate matrix - Glass fiber composite and its comparison to Portland cement-based composites, Constr. Build. Mater. 93 (2015) 360-370. doi:10.1016/j.conbuildmat.2015.06.011.

[36] S. Das, D. Stone, B. Mobasher, N. Neithalath, Strain energy and process zone based fracture characterization of a novel iron carbonate binding material, Eng. Fract. Mech. 156 (2016) 115. doi:10.1016/j.engfracmech.2016.01.024.

[37] O. Bernard, F.-J. Ulm, E. Lemarchand, A multiscale micromechanics-hydration model for the early-age elastic properties of cement-based materials, Cem. Concr. Res. 33 (2003) 12931309.

[38] Zaoui André, Continuum Micromechanics: Survey, J. Eng. Mech. 128 (2002) 808-816.

[39] B.D. Lubachevsky, F.H. Stillinger, E.N. Pinson, Disks vs. spheres: Contrasting properties of random packings, J. Stat. Phys. 64 (1991) 501-524.

[40] B.D. Lubachevsky, F.H. Stillinger, Geometric properties of random disk packings, J. Stat. Phys. 60 (1990) 561-583.

[41] S. Das, A. Maroli, S.S. Singh, T. Stannard, X. Xiao, N. Chawla, N. Neithalath, A microstructure-guided constitutive modeling approach for random heterogeneous materials: Application to structural binders, Comput. Mater. Sci. 119 (2016) 52-64.

[42] S. Das, M. Aguayo, S.D. Rajan, G. Sant, N. Neithalath, Microstructure-guided numerical simulations to predict the thermal performance of a hierarchical cement-based composite material, Cem. Concr. Compos. 87 (2018) 20-28. 
[43] S. Nayak, S. Das, A microstructure-guided numerical approach to evaluate strain sensing and damage detection ability of random heterogeneous self-sensing structural materials, Comput. Mater. Sci. 156 (2019) 195-205.

[44] S. Nayak, N.M.A. Krishnan, S. Das, Microstructure-guided numerical simulation to evaluate the influence of phase change materials (PCMs) on the freeze-thaw response of concrete pavements, Constr. Build. Mater. 201 (2019) 246-256.

[45] O. van der Sluis, P.J.G. Schreurs, W.A.M. Brekelmans, H.E.H. Meijer, Overall behaviour of heterogeneous elastoviscoplastic materials: effect of microstructural modelling, Mech. Mater. 32 (2000) 449-462.

[46] S. Das, P. Yang, S.S. Singh, J.C.E. Mertens, X. Xiao, N. Chawla, N. Neithalath, Effective properties of a fly ash geopolymer: Synergistic application of X-ray synchrotron tomography, nanoindentation, and homogenization models, Cem. Concr. Res. 78 (2015) 252-262.

[47] H.A. Meier, E. Kuhl, P. Steinmann, A note on the generation of periodic granular microstructures based on grain size distributions, Int. J. Numer. Anal. Methods Geomech. 32 (2008) 509-522.

[48] S. Das, C. Hoffarth, B. Ren, B. Spencer, G. Sant, N. Neithalath, Simulating the Fracture of Notched Mortar Beams through Extended Finite Element Method (XFEM) and Peridynamics, (2019) 26.

[49] M.P. Lutz, P.J.M. Monteiro, R.W. Zimmerman, Inhomogeneous interfacial transition zone model for the bulk modulus of mortar, Cem. Concr. Res. 27 (1997) 1113-1122.

[50] S. Diamond, J. Huang, The ITZ in concrete - a different view based on image analysis and SEM observations, Cem. Concr. Compos. 23 (2001) 179-188.

[51] S. Das, M. Aguayo, N. Kabay, B. Mobasher, G. Sant, N. Neithalath, Elucidating the influences of compliant microscale inclusions on the fracture behavior of cementitious composites, Cem. Concr. Compos. 94 (2018) 13-23.

[52] S. Das, A. Maroli, N. Neithalath, Micromechanical Modeling for Material Design of Durable Infrastructural Materials: The Influence of Aggregate and Matrix Modification on Elastic Behavior of Mortars, in: Int. Conf. Durab. Concr. Struct., 2016.

[53] Z. Xu, H. Hao, H.N. Li, Mesoscale modelling of dynamic tensile behaviour of fibre reinforced concrete with spiral fibres, Cem. Concr. Res. 42 (2012) 1475-1493.

[54] M.G. da Silva, K.T. Ramesh, The rate-dependent deformations of porous pure iron, Int. J. Plast. 13 (1997) 587-610.

[55] S. Da, J. Němeček, P. Štemberk, Application of multiscale elastic homogenization based on nanoindentation for high performance concrete, Adv. Eng. Softw. 62-63 (2013) 109-118.

[56] T. Wu, P. Wriggers, Multiscale diffusion-thermal-mechanical cohesive zone model for concrete, Comput. Mech. 55 (2015) 999-1016.

[57] G. Li, Y. Zhao, S.-S. Pang, Four-phase sphere modeling of effective bulk modulus of concrete, Cem. Concr. Res. 29 (1999) 839-845.

[58] M. Hain, P. Wriggers, Numerical homogenization of hardened cement paste, Comput. Mech. 42 (2008) 197-212.

[59] Yamamuro Jerry A., Abrantes Antonio E., Lade Poul V., Effect of Strain Rate on the StressStrain Behavior of Sand, J. Geotech. Geoenvironmental Eng. 137 (2011) 1169-1178. 